\title{
Decaimento das emissões de biogás após um ano do encerramento de um aterro controlado de uma cidade de 500.000 habitantes
}

\section{Decay of biogas emissions after one year of closure of 500.000 habitants city}

\author{
Adriano Quadros ${ }^{1}$; Jorge Luiz Audibert ${ }^{2}$; \\ Fernando Fernandes ${ }^{3}$
}

\section{Resumo}

Este trabalho apresenta resultados de medidas que permitem avaliar o decaimento das emissões de biogás no aterro controlado de Londrina (Limoeiro), após um ano de fechamento e uma comparação com as previsões de três modelos matemáticos. Foram realizadas medidas na camada de superfície através de ensaios de placa estática de fluxo e também nos drenos verticais. A emissões totais de metano foram de 9.602.192 $\mathrm{Nm}^{3}$. ano ${ }^{-1}$ e as de biogás foram de $21.117 .824 \mathrm{Nm}^{3}$. ano ${ }^{-1}$. Em comparação com as últimas medidas antes de fechamento do aterro, houve uma redução de $38 \%$ na emissão de biogás após o período de um ano. Os valores previstos pelos modelos matemáticos foram 55\%, 69\% e 57\% maiores do que o valor medido, para os modelos Triangular, Scholl Canyon e Software Landgem 3.02, respectivamente.

Palavras-chave: Biogás. Metano. Aterro Controlado. Modelos Matemáticos. Decaimento das Emissões.

\begin{abstract}
This paper presents results on the decay of the emission of biogas in Londrina's landfill (Limoeiro) after one year of closure and a comparison with the predictions of three mathematical models. Measurements were performed on the surface layer by static closed chamber tests and also in vertical drains. The total methane emissions were 9,602,192 $\mathrm{Nm}^{3}$.year ${ }^{-1}$ and the total biogas were 21,117,824 $\mathrm{Nm}^{3}$.year ${ }^{-1}$. Compared with the latest measures before closing the landfill, there was a reduction of $38 \%$ of biogas after one year. The values predicted by the mathematical models were $55 \%, 69 \%$ and $57 \%$ higher than the measured value for the triangular pattern, Scholl Canyon and Software Landgem 3.02, respectively.

Keywords: Biogas. Methane. Landfill. Mathematical Models. Emission Decay.
\end{abstract}

\footnotetext{
${ }^{1}$ Me. em Engenharia de Edificações e Saneamento, UEL, Londrina, Pr, Brasil; E-mail: adrianoquadros@ @otmail.com

${ }^{2}$ Me. em Engenharia de Edificações e Saneamento, UEL, Londrina, Pr, Brasil; E-mail: jmaudibert@ sercomtel.com.br

${ }^{3}$ Prof. Dr. Depto. de Construção Civil, CTU/UEL, Londrina, Pr, Brasil; E-mail: fernando@uel.br
} 


\section{Introdução}

Aterros sanitários e controlados são a forma de destinação final de resíduos sólidos urbanos mais utilizada no Brasil em virtude de sua simplicidade de execução e baixo custo, além de facilidade operacional. Dentre os problemas ambientais decorrentes dessa prática encontra-se a geração de biogás a partir da decomposição dos resíduos e o lixiviado, efluente líquido, também conhecido como chorume (ENSINAS, 2003).

$\mathrm{O}$ aterramento de resíduos é apontado, juntamente com o tratamento anaeróbio de esgotos domésticos e efluentes industriais, como uma das maiores fontes de metano liberado para a atmosfera, contribuindo assim para o agravamento do efeito estufa. Segundo IPCC (1996) os aterros são responsáveis por 5 a $20 \%$ do total de metano liberado por fontes com origem antrópica.

O biogás é formado a partir da degradação anaeróbia da matéria orgânica. Sua produção ocorre a partir de uma grande variedade de resíduos orgânicos tais como os resíduos domésticos, resíduos de atividades agrícolas e pecuárias, lodo de esgoto, entre outros. Sua composição média é de $60 \%$ de metano, $35 \%$ de dióxido de carbono e $5 \%$ de uma mistura de outros gases como hidrogênio, nitrogênio, gás sulfídrico, monóxido de carbono, amônia, oxigênio e aminas voláteis. Dependendo da eficiência do processo, o biogás chega a conter entre $40 \%$ e $80 \%$ de metano (PECORA, 2006).

A digestão anaeróbia de compostos orgânicos é um processo microbiano de flora mista, onde a matéria orgânica, na ausência de oxigênio molecular, é convertida em gases compostos predominantemente de metano e dióxido de carbono (MASSEY e POHLAND, 1978). Esse processo ocorre em dois estágios. No primeiro estágio atuam bactérias anaeróbias e facultativas, denominadas formadoras de ácidos, onde, segundo FUENTES et al. (2008), compostos orgânicos complexos do tipo carboidratos, lipídios e proteínas são convertidos em outros compostos mais simples, principalmente, ácidos voláteis. No segundo estágio atuam bactérias estritamente anaeróbias, as quais convertem os ácidos orgânicos em produtos finais gasosos como metano e gás carbônico.

A formação e a taxa de geração dos principais constituintes do biogás de aterro são variáveis ao longo do tempo e seguem várias fases distintas que podem ser observadas na Figura 1. Na fase I a decomposição biológica da matéria orgânica ocorre principalmente em condições aeróbias, na fase II a quantidade de oxigênio é reduzida e as reações anaeróbias começam a se desenvolver. $\mathrm{Na}$ fase III as reações que começaram a ocorrer na fase II, agora são intensificadas, produzindo quantidades significativas de ácidos orgânicos. Na fase IV ocorre a produção simultânea de metano e de ácidos orgânicos, embora a produção de ácidos seja reduzida. $\mathrm{Na}$ fase $\mathrm{V}$, grande parte do material biodegradável já foi consumido e a produção de biogás é reduzida consideravelmente.

Figura 1: Fases de formação do biogás de aterro ao longo do tempo

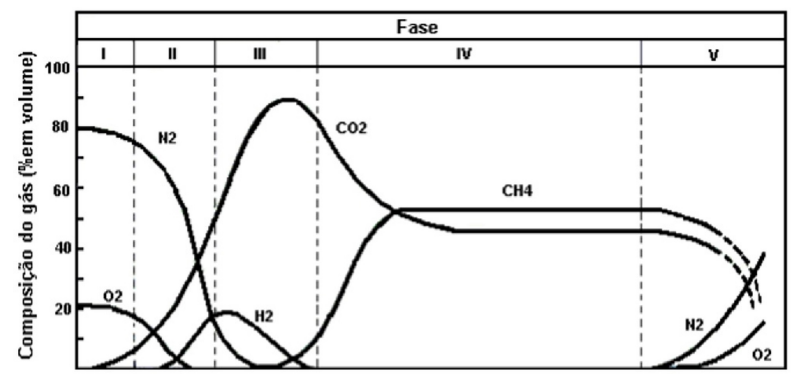

Fonte: Adaptado de (TCHOBANOGLOUS; THEISEN \& VINIL, 1993).

Segundo Tchobanoglous, Theisen \& Vinil (1993), a duração de cada fase na produção do gás do aterro depende da distribuição da matéria orgânica no aterro, da disponibilidade de nutrientes, do teor de umidade dos resíduos e do grau de compactação inicial dos resíduos.

A complexidade dos estudos sobre aterros se origina na diversidade de fatores que influem na produção final dos subprodutos da biodegradação. Nos aterros de resíduos sólidos domésticos (RSD), as condições são alteradas continuamente por diversos fatores, vários deles sem possibilidade de controle (AUDIBERT, 2010).

Neste estudo são apresentados resultados de um trabalho de quantificação e qualificação do biogás emitido no aterro controlado de Londrina-PR, conhecido como aterro do Limoeiro. As medidas de emissão foram realizadas na época do encerramento do aterro e um ano após o encerramento. As medidas foram realizadas nos drenos de gás e na camada de cobertura, com placas estáticas. Como em geral são utilizados modelos matemáticos para se estimar a emissão de biogás em aterros sanitários, neste trabalho, as medições feitas no local foram comparadas com aquelas previstas por três dos modelos mais utilizados. Embora a segunda medição, realizada 1 ano após o encerramento tenha sido prejudicada pela falta de manutenção do local, o que implicou em fugas de gás, ainda assim, o trabalho apresenta um comparativo relevante sobre a redução de emissões após o encerramento de um aterro nas condições brasileiras. 


\section{Material e Métodos}

\section{Local do trabalho}

A cidade de Londrina está localizada no norte do estado do Paraná e tem população de aproximadamente 500.000 habitantes. Trata-se de um município relativamente novo com 78 anos de fundação e, atualmente, 97\% de sua população residem no núcleo urbano da cidade (IBGE, 2010). As precipitações no município são mais intensas nos meses de verão e a média anual é de 1606 $\mathrm{mm}$. A temperatura média anual é de $21,1^{\circ} \mathrm{C}$ (IAPAR, 2010).

De acordo com antigos funcionários da prefeitura de Londrina, o local, conhecido como aterro do Limoeiro, começou a receber resíduos em 1979, sem qualquer preparo da área. Ao longo do tempo a área recebeu algumas melhorias, tais como drenos de gás e lixiviados, tratamento de lixiviado e drenagem pluvial, além da cobertura dos resíduos com terra. Porém há pouca documentação a respeito da área.

Alguns projetos de adequação da área seguiram como critérios básicos de operação, a facilidade de manobras e a disponibilidade de espaço no terreno. Os resíduos eram depositados em camadas de aproximadamente 4 metros de altura, compactados por tratores de esteira e então recobertos por uma camada de solo do local, de acordo com os projetos de readequação analisados.

Para efeitos das medidas de emissão de biogás, aterro foi dividido em 3 áreas, de acordo com a idade média dos resíduos depositados em cada uma das áreas. A figura 2 mostra essa divisão.

Figura 2: Levantamento planialtimétrico do aterro controlado de Londrina realizado em outubro de 2009.

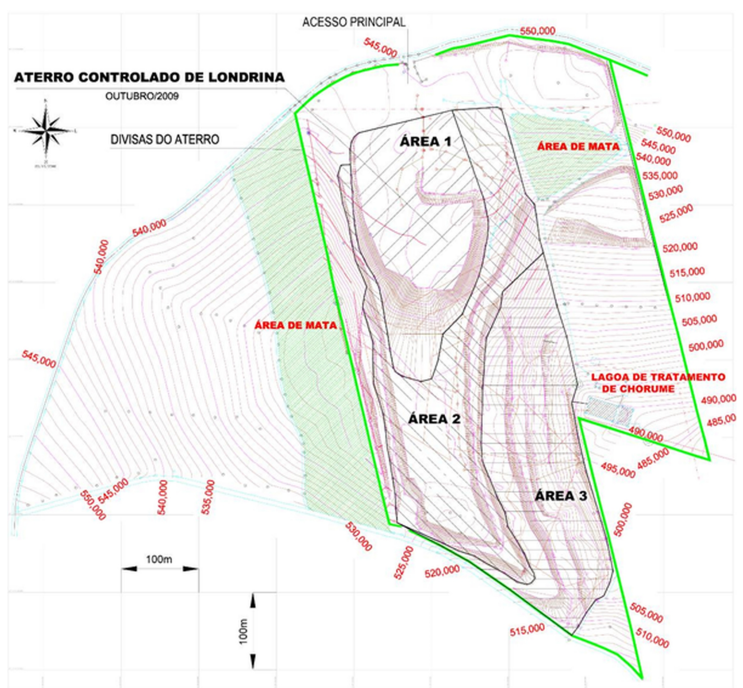

Fonte: Próprio autor.
A área 1 é onde estão depositados os resíduos mais recentes, com cerca de 3 anos. Na área 2 estão depositados resíduos com idade entre 3 e 7 anos e na área 3 estão depositados os resíduos mais antigos, com idade superior a 7 anos. As dimensões de cada área são as seguintes: área 1 com $51.535 \mathrm{~m}^{2}$, área 2 com $50.506 \mathrm{~m}^{2}$ e, área 3 com $49.852 \mathrm{~m}^{2}$.

\section{Medições da emissão de biogás}

Para os ensaios realizados na camada de cobertura foi utilizada uma placa estática de fluxo, com dimensões de $0,40 \mathrm{~m} \times 0,40 \mathrm{~m} \times 0,05 \mathrm{~m}$, que resultam num volume interno de $8 \mathrm{~L}$, de acordo com a metodologia desenvolvida por Maciel (2003). Para as medidas de composição do gás foi utilizado um detector de gases $\left(\mathrm{CH}_{4}, \mathrm{CO}_{2}, \mathrm{O}_{2} \mathrm{e}\right.$ $\mathrm{H}_{2} \mathrm{~S}$ ) modelo X-am 7000 da marca Draeger. Para as medidas de temperatura foi utilizado um termômetro digital com sensor marca Lutron modelo TM-902 C. A pressão atmosférica necessária para a realização dos cálculos de normalização do volume dos gases foi fornecida pelo Instituto Agronômico do Paraná (IAPAR) - Estação Londrina e ajustada para a altitude do aterro.

Para os ensaios realizados nos drenos verticais foi utilizado, além do detector de gases, um termo-anemômetro marca Airflow modelo TA35 com faixa de 0 a 20 m.s ${ }^{-1}$, resolução de $0,01 \mathrm{~m} . \mathrm{s}^{-1}$ e termômetro de 0 a $80^{\circ} \mathrm{C}$. As medidas de velocidade do biogás eram feitas em pelo menos três pontos da seção interna dos tubos. Os dados obtidos em campo foram submetidos à normalização através da equação dos gases ideais.

A quantificação de metano e de gás carbônico foi feita a partir da média estatística dos valores obtidos nos ensaios de placa de fluxo realizados em cada uma das áreas. A soma dos valores de emissão obtidos para cada gás resultou no volume total de biogás.

Foram realizados 35 ensaios de placa e ensaios em todos os 17 drenos ainda presentes no aterro, os drenos anteriormente denominados 1, 6, 9 a 12 e 23 foram extintos após um ano de enceramento. A localização dos ensaios e dos drenos está representada na figura 3 .

Os resultados das medidas obtidas um ano após o encerramento do aterro foram comparados com as medidas no mesmo local, realizadas por Audibert, em 2010, alguns meses antes do encerramento do aterro.

\section{Modelos matemáticos utilizados}

A seguir são apresentadas as equações que definem cada um dos modelos. 
Figura 3: Levantamento planialtimétrico simplificado do aterro controlado de Londrina com a localização dos pontos de medição

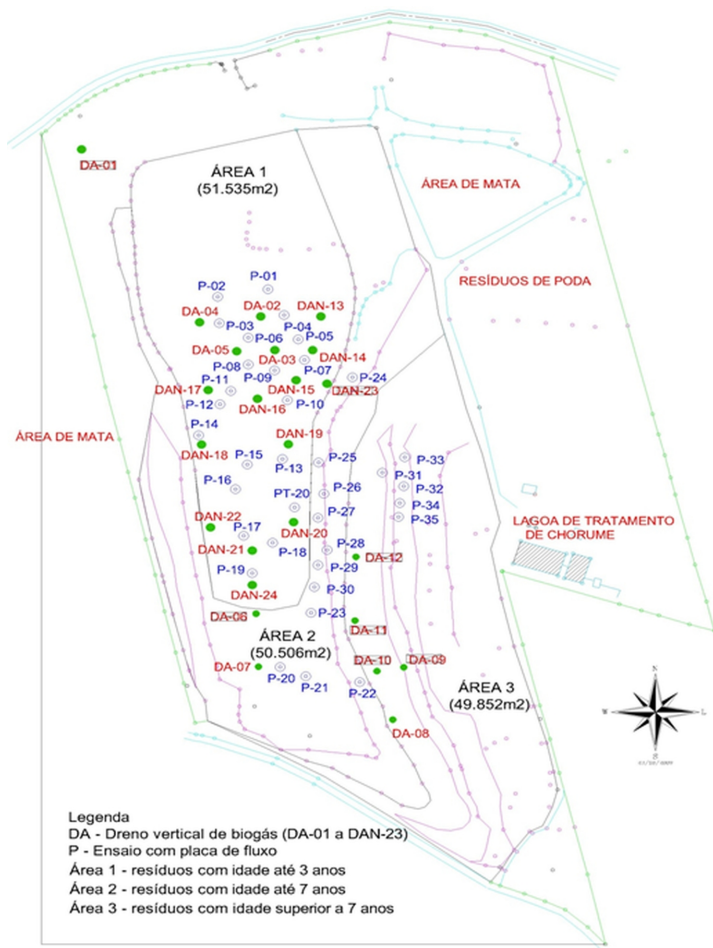

Fonte: Próprio autor.

A equação (1) define o modelo Scholl Canyon.

$$
Q_{C H 4}=L_{0} \times R \times\left(e^{-k \times c}-e^{-k \times t}\right)
$$

onde:

$Q_{C H 4}=$ quantidade de metano produzida por ano $\left(\mathrm{m}^{3} / \mathrm{ano}\right)$,

$\mathrm{k}=$ taxa de geração de metano $\left(0,05 \mathrm{ano}^{-1}\right)$,

$\mathrm{L}_{0}=$ potencial da geração de metano $\left(170 \mathrm{~m}^{3}\right.$ de $\mathrm{CH}_{4} /$ ton.resíduo),

$\mathrm{R}=$ taxa média anual de resíduos sólidos recebidos durante a vida ativa do aterro (t/ano)

$\mathrm{t}$ = tempo desde o início do depósito dos RSD (anos)

$\mathrm{c}=$ tempo desde $\mathrm{o}$ fechamento do aterro $(\operatorname{anos}) ; \mathrm{c}=0$ para aterros ativos

e = base log, sem unidade .

A equação (2) é a equação utilizada pelo software Landgem 3.02.

$$
Q_{C H 4}=\sum_{i=1}^{n} \sum_{j=0.1}^{1} k \times L_{0} \times\left[\frac{M_{i}}{10}\right] \times\left(e^{-k \times t_{i} \times j}\right)
$$

onde:

$Q_{C H 4}=$ quantidade de metano produzida por ano $\left(\mathrm{m}^{3} / \mathrm{ano}\right)$ $\mathrm{i}=1$ - tempo em anos a ser incrementado

$\mathrm{n}=$ ano do inventário

$\mathrm{j}=0,1$ - tempo em anos a ser incrementado

$\mathrm{k}=$ taxa de geração de metano $\left(0.052018^{-1}\right)$

$\mathrm{L}_{0}=$ potencial da geração de metano $\left(170 \mathrm{~m}^{3}\right.$ de $\mathrm{CH}_{4}$ /ton.resíduo)

$\mathbf{M}_{i}=$ massa de resíduos sólidos recebidos no ano "i"(ton./ano)

t= idade da seção "j"dos resíduos $\mathrm{M}_{i}$ recebidos no ano "i"

As equações (3) e (4) são utilizadas no modelo triangular para se calcular o volume de metano produzido por unidade de massa de resíduo.

$$
\begin{aligned}
& \mathrm{CaHbOcNd}+\frac{(4 a-b-2 c+3 d)}{4} \times \mathrm{H}_{2} \mathrm{O} \rightarrow \\
& \rightarrow \quad \frac{(4 a-b-2 c-3 d)}{8} \times \mathrm{CH}_{4} \\
& +\frac{(4 a-b+2 c+3 d)}{8} \times\left(\mathrm{CO}_{2}+d \mathrm{CO}_{2}+d\right) \times \mathrm{NH}_{3}
\end{aligned}
$$




$$
V C H_{4}=M s \times \frac{\left(\mathrm{MCH}_{4}\right)}{\left(\mathrm{MCaHbOcNd} \times \rho \mathrm{CH}_{4}\right)}
$$

onde:

$\mathrm{CH}_{4}=$ volume unitário de gás metano $\left(\mathrm{m}^{3} / \mathrm{kg}\right)$

$\mathrm{M}_{s}=$ massa seca de resíduos (RB ou LB) $(\mathrm{kg})$

$\mathrm{M}_{\mathrm{CH} 4}=$ massa de gás metano obtido na equação (3) (kg)

$\mathrm{M}_{\mathrm{CaHbOcNd}}=$ massa da matéria orgânica obtida na equação (3) $(\mathrm{kg})$

$\rho \mathrm{CH} 4=$ massa específica do gás metano $\left(0,716 \mathrm{~kg} / \mathrm{m}^{3}\right)$.

\section{Resultados e Discussão}

Medidas realizadas um ano após o encerramento do aterro

Após o encerramento do aterro controlado, a área não recebeu nenhuma manutenção por parte da prefeitura, portanto as medidas realizadas um ano após o fechamento foram prejudicadas: alguns drenos foram destruídos, havia fendas em alguns locais devido a recalques e a erosão havia carreado a camada de cobertura em alguns pontos. Portanto é preciso levar em conta que as medidas de emissão foram realizadas nestas condições.

A Tabela 1 apresenta os resultados das medidas realizadas. Os pontos de 1 a 19 estão localizados na área 1; os de 20 a 30, na área 2 e os de 31 a 35, na área 3.

Observa-se, na Tabela 1, uma grande variação dos valores medidos, o que pode ser explicado, em parte, pela falta de manutenção da área, com fissuras na camada de cobertura, o que permite a fuga do biogás. Isto efetivamente foi constatado no local em função do odor característico do processo de biodegradação.

As medidas realizadas nos drenos de gás são apresentadas na Tabela 2 a seguir.

Observa-se, na Tabela 2, que a maioria dos drenos estão localizados na área 1, a mais recente. Nas áreas 2 e 3 , havia apenas 1 dreno operacional em cada. A maioria dos drenos apresentaram inclinações devido a recalques sofridos ao longo do tempo e à ausência de manutenção. Em vários deles, foi observado vazamento de biogás na base dos mesmos, sendo que esta fuga de biogás não pode ser quantificada.

As médias de emissão dos pontos medidos em cada área permitiram a estimativa total das emissões nas áreas 1,2 e 3 , bem como dos drenos de gás, como pode ser visto na Tabela 3
Tabela 1: Resultado das medidas realizadas um ano após o encerramento do aterro, em 35 pontos da camada de cobertura, utilizando as placas estáticas.

\begin{tabular}{cc|cc}
\hline Ensaio Emissão de $\mathrm{CH}_{4}$ & Ensaio & $\begin{array}{c}\text { Emissão de } \mathrm{CH}_{4} \\
\left(\mathrm{Nm}^{3} \cdot \mathrm{m}^{-2} \cdot \mathrm{mo}^{-2} \cdot \mathrm{ano}^{-1}\right)\end{array}$ \\
\hline 1 & 10,24 & 19 & 25,94 \\
2 & 21,34 & 20 & 15,38 \\
3 & 157,58 & 21 & 14,76 \\
4 & 46,42 & 22 & 197,24 \\
5 & 18,41 & 23 & 203,02 \\
6 & 21,69 & 24 & 206,75 \\
7 & 51,44 & 25 & 105,96 \\
8 & 49,59 & 26 & 371,15 \\
9 & 52,61 & 27 & 27,93 \\
10 & 31,96 & 28 & 16,48 \\
11 & 122,21 & 29 & 24,88 \\
12 & 57,53 & 30 & 84,04 \\
13 & 39,33 & 31 & 8,43 \\
14 & 15,24 & 32 & 6,01 \\
15 & 24,60 & 33 & 11,17 \\
16 & 11,17 & 34 & 0,00 \\
17 & 176,98 & 35 & 6,68 \\
18 & 8,11 & & \\
\hline & & &
\end{tabular}

Fonte Próprio autor.

O resultado das emissões totais medidas foram, portanto, de 9.602.191 Nm .ano $^{-1}$. Cerca de $90 \%$ das emissões medidas $\left(8.778 .664 \mathrm{Nm}^{3}\right.$.ano $\left.{ }^{-1}\right)$ passaram através da camada de cobertura e apenas em torno de $10 \%$ foram extraídos pelos drenos de gás.

O baixo desempenho dos drenos de gás se deve, em parte, à falta de manutenção do aterro.

\section{Comparação entre as emissões medidas no encerramento e um ano após}

Tendo por base o trabalho realizado por Audibert (2010), que empregou a mesma metodologia em medições realizadas poucos meses antes do encerramento do aterro, a Tabela 4 apresenta as emissões médias das 3 áreas e as emissões medidas nos drenos de gás.

A Tabela 4 mostra uma grande redução na emissão tanto pela camada de cobertura como pelos drenos de gás. É natural haver uma redução nas emissões de biogás, uma vez que, com o encerramento do aterro, não houve mais deposição de matéria orgânica no local.

A Tabela 5 apresenta o comparativo das emissões totais no encerramento e um ano após o encerramento do aterro. 
Quadros, A. ${ }^{1}$; Audibert, J.L. ${ }^{2}$; Fernandes, F. ${ }^{3}$

Tabela 2: Emissão de $\mathrm{CH}_{4}$ nos drenos de gás operacionais, um ano após o encerramento do aterro.

\begin{tabular}{cc|cc|cc}
\hline Dreno & $\begin{array}{c}\text { Vazão de } \mathrm{CH}_{4} \\
\left(\mathrm{Nm}^{3} \cdot \mathrm{h}^{-1}\right)\end{array}$ & Dreno & $\begin{array}{c}\text { Vazão de } \mathrm{CH}_{4} \\
\left(\mathrm{Nm}^{3} \cdot \mathrm{h}^{-1}\right)\end{array}$ & Dreno & $\begin{array}{c}\text { Vazão de } \mathrm{CH}_{4} \\
\left(\mathrm{Nm}^{3} \cdot \mathrm{h}^{-1}\right)\end{array}$ \\
\hline DA-02 & 0,11 & DAN-13 & 3,25 & DAN-19 & 2,89 \\
DA-03 & 1,68 & DAN-14 & 4,08 & DAN-20 & 1,39 \\
DA-04 & 1,06 & DAN-15 & 1,33 & DAN-21 & 4,97 \\
DA-05 & 2,38 & DAN-16 & 3,46 & DAN-22 & 18,08 \\
DA-07 & 19,75 & DAN-17 & 1,35 & DAN-24 & 0,41 \\
DA-08 & 6,08 & DAN-18 & 21,74 & & \\
\hline
\end{tabular}

Fonte: Próprio autor.

Tabela 3: Emissão de $\mathrm{CH}_{4}$ nos drenos de gás operacionais, um ano após o encerramento do aterro.

\begin{tabular}{|c|c|c|c|c|}
\hline Emissão na Área 1 & Emissão na Área 2 & Emissão na Área 3 & \multirow{2}{*}{$\begin{array}{c}\text { Emissão nos drenos de gás } \\
\left(\mathrm{Nm}^{3} \cdot \mathrm{ano}^{-1}\right)\end{array}$} & \multirow{2}{*}{$\begin{array}{c}\text { Total } \\
\left(\mathrm{Nm}^{3} \cdot \mathrm{ano}^{-1}\right)\end{array}$} \\
\hline & $\left(\mathrm{Nm}^{3} \cdot \mathrm{ano}^{-1}\right)$ & & & \\
\hline 2.556 .057 & 5.820 .092 & 402.514 & 823.528 & 9.602 .191 \\
\hline
\end{tabular}

Fonte: Próprio autor.

Tabela 4: Emissões médias de $\mathrm{CH}_{4}$ na camada de cobertura e nos drenos de gás no intervalo de 1 ano após o encerramento do aterro.

\begin{tabular}{cccccccc}
\hline Ano & Área 1 & Área 2 & Área 3 & & Drenos da Área 1 & Drenos da Área 2 & Drenos da Área 3 \\
\cline { 2 - 3 } \cline { 6 - 7 } & \multicolumn{3}{c}{$\left(\mathrm{Nm}^{3} \cdot \mathrm{m}^{-2} \cdot \mathrm{ano}^{-1}\right)$} \\
\hline 2010 & 60,1 & 198,7 & 42,5 & & 118,2 & 34,1 & 16,4 \\
2011 & 49,6 & 115,2 & 8,0 & & 68,2 & 19,8 & 6,1 \\
\hline
\end{tabular}

Fonte: Próprio autor.

Analisando a Tabela 5, observa-se que houve uma redução total de aproximadamente $42 \%$ no intervalo de 1 ano. Em parte, isto se deve à fuga de gás devido à falta de manutenção do aterro, porém o decaimento na produção certamente é muito alto, embora seja impossível determinar com exatidão, justamente por conta dos problemas de manutenção da área. Também deve ser observado que a área não foi planejada para o aproveitamento do biogás.

O total da emissão de biogás em 2010 foi de 34.352.446 ( $\mathrm{Nm}^{3}$.ano $\left.{ }^{-1}\right)$ e em 2011, de 21.117.824 $\left(\mathrm{Nm}^{3}\right.$.ano $\left.{ }^{-1}\right)$, observando-se um decaimento de aproximadamente $38 \%$ em um ano. Este dado é coerente, já que se nota uma redução do teor de $\mathrm{CH}_{4}$ no biogás ao longo do tempo.

A mesma metodologia foi utilizada para avaliar a emissão de $\mathrm{CO}_{2}$, com valor total estimado em 17.446.644 $\left(\mathrm{Nm}^{3} \cdot \mathrm{ano}^{-1}\right)$ em 2010 e $10.776 .228\left(\mathrm{Nm}^{3} \cdot \mathrm{ano}^{-1}\right)$ em 2011.

A geração e a composição do biogás nos aterros dependem da composição dos resíduos presentes, mas a taxa de bioconversão do material orgânico pode sofrer influência de diversos fatores, tais como: aspectos ambientais, o manejo do aterro e os parâmetros físico-químicos, que na maioria das vezes estão relacionados entre si (ALCÂNTRA e JUCÁ, 2011)

Comparação das medidas com as estimativas obtidas através de modelos matemáticos

Audibert (2011) também estimou a produção de biogás no aterro controlado de Londrina a partir modelos matemáticos e também a produção após o encerramento do aterro. Os modelos matemáticos utilizados foram, o modelo triangular de Tchobanoglous, Theisen \& Vigil (1993), o modelo Scholl Canyon (USEPA, 1998) e também o software Landgem 3.02 (ALEXANDER et al., 2005).

A Tabela 6 mostra as estimativas de emissão de metano para cada um dos modelos em 2011, considerando a desativação do aterro em 2010.

Em comparação com o valor medido na campanha realizada, 9.602.192 N.m ${ }^{3}$.ano ${ }^{-1}$, os modelos matemáticos preveem valores $55 \%$, $69 \%$ e $57 \%$ maiores para os modelos Triangular, Scholl Canyon e Software Landgem 3.02, respectivamente. Essa diferença em parte pode ser justificada pelo fato do aterro não ter sido projetado para captação do biogás, porém é razoável supor que os modelos matemáticos superestimam a produção de biogás, principalmente após seu encerramento. 
Tabela 5: Emissões médias de $\mathrm{CH}_{4}$ na camada de cobertura e nos drenos de gás no intervalo de 1 ano após o encerramento do aterro.

\begin{tabular}{|c|c|c|c|c|c|c|c|}
\hline \multirow[t]{2}{*}{ Ano } & Área 1 & Área 2 & Área 3 & Drenos da Área 1 & Drenos da Área 2 & Drenos da Área 3 & \multirow{2}{*}{$\begin{array}{c}3 \text { Total } \\
\left(\mathrm{Nm}^{3} \cdot h^{-1}\right)\end{array}$} \\
\hline & \multicolumn{2}{|c|}{$\left(\mathrm{Nm}^{3} \cdot \mathrm{m}^{-2} \cdot\right.$ ano $\left.^{-1}\right)$} & & & $\left(\mathrm{Nm}^{3} \cdot \mathrm{h}^{-1}\right)$ & & \\
\hline 2010 & 3.097 .769 & 10.035542 & 2.119 .209 & 1.035 .169 & 299.066 & 143.664 & 16.730 .419 \\
\hline 2011 & 2.556 .057 & 5.820 .092 & 402.514 & 597.257 & 173.010 & 53.261 & 9.602 .191 \\
\hline
\end{tabular}

Fonte: Próprio autor.

Tabela 6: Estimativa de emissões de metano no aterro controlado de Londrina em 2011, segundo diversos modelos.

\begin{tabular}{cc}
\hline Modelo & $\begin{array}{c}\text { Estimativa } \\
\text { de produção em 2001 } \\
\left(\mathrm{Nm}^{3} \text { de } \mathrm{CH}_{4} / \mathrm{ano}\right)\end{array}$ \\
\hline Modelo Triangular & 14.887 .427 \\
Modelo Scholl Canyon & 16.273 .427 \\
Software Landgem 3.02 & 15.107 .565 \\
Medidas locais em 2011 & 9.602 .191 \\
\hline
\end{tabular}

Fonte: Próprio autor.

\section{Conclusões}

O valor total das emissões de metano medidas em 2010 foi de $16.730 .419 \mathrm{Nm}^{3}$.ano ${ }^{-1}$. O valor total das emissões de metano medidas em 2011 foi de $9.602 .191 \mathrm{Nm}^{3}$. ano ${ }^{-1}$.

A queda nas emissões de biogás e de metano é decorrente do encerramento, e consequente ausência de deposição de matéria orgânica. Porém a falta de manutenção também influenciou nas medidas

Os modelos matemáticos previram valores 55\%, $69 \%$ e $57 \%$ maiores do que o valor obtido com as medidas locais, para os modelos Triangular, Scholl Canyon e Software Landgem 3.02, respectivamente. Mesmo com as limitações devido à falta de manutenção do aterro, é muito provável que os modelos matemáticos levem a números superestimados de produção de metano para as condições brasileiras após o encerramento dos aterros.

\section{Referências}

ALCÂNTARA, P.B.; JUCÁ, J.F.T. Recalque em aterros: influência da composição dos resíduos sólidos urbanos, do clima e da biodegradação. Geotecnia, Lisboa, n. 118, p. 15-42, mar. 2010.

AUDIBERT, J.L. Avaliação qualitativa e quantitativa da produção de biogás do aterro controlado de Londrina. 2011. Dissertação (Mestrado Eng. de Edificações e Saneamento) - Universidade Estadual de Londrina, Londrina. 2011.
ENSINAS, A. V. Estudo da geração de biogás no aterro sanitário delta em Campinas - SP. 2003. Dissertação (Mestrado em Engenharia de Edificações e Saneamento) Universidade Estadual de Campinas, Campinas. 2003.

FUENTES, M.; SCENNA, N. J.; AGUIRRE, P. A.; MUSSATI, M. C. Application of two anaerobic digestion models to biofilm systems. Biochemical Engineering Journal, Amsterdam, v. 38, 2008. https://doi.org/10.1016/ j.bej.2007.07.013.

INSTITUTO AGRONÔMICO DO PARANÁ - IAPAR. Cartas climáticas do Paraná. 2010.Disponível em: <http://www.iapar.br/modules/conteudo/ conteudo. php? conteudo=677>.

IBGE. 2010. Disponível em: <www.ibge.gov.br> Acesso em: 10 nov. 2011.

INTERGOVERNMENTAL PANEL ON CLIMATE CHANGE - IPCC. Guia para inventários nacionais de gases de efeito estufa. Módulo 6: Lixo. 1996. v. 2 Disponível em: <http://www .ipcc-nggip.iges.or.jp/ public/gl/invs6.html>. Acesso em: 20 ago. 2011.

MACIEL, F.J. Estudo da geração, percolação e emissão de gases no aterro de resíduos sólidos da Muribeca/Pe. 2003. Dissertação (Mestrado em Engenharia Civil) - Universidade Federal de Pernambuco, Recife, 2003.

MASSEY, M. L.; POHLAND, F. G. Phase separation of anaerobic stabilization by kinetic controls. Journal Water Pollution Control Federation, Washington, v. 50, p. 22042222, 1978

PECORA, V. Implantação de uma unidade demonstrativa de geração de energia elétrica a partir do biogás de tratamento do esgoto residencial da USP: estudo de caso. 2006. Dissertação (Mestrado em Energia) - Universidade de São Paulo, São Paulo, 2006.

TCHOBANOGLOUS, G.; THEISEN, H.; VIGIL, S. Integrated solid waste management: engineering principles and management issues. Irwin: MacGraw-Hill, 1993. 978p. 
UNITED STATES ENVIRONMENTAL PROTECTION

AGENCY. Municipal Solid Waste Landfills, Related Information. In:In: Air emissions factors and quantification. [S.l.: s. n.], 2016. AP 42 Section 2.4. Disponível em: <http://www.epa.gov/ttn/chief/ap42/ch02/ final/c02s04.pdf>. Acesso em: nov. 2011.

ALEXANDER, A.; BURKLIN, C.; SINGLETON, A. Landfill gas emissions model (LandGEM) Version 3.02 User's Guide. May 2005. Disponível em: <http://www.epa.gov/ttn/catc/dir1/ landgem-v302-guide.pdf>. Acesso em: nov. 2011. 